\title{
Malignant mesothelioma of the tunica vaginalis testis: a malignancy associated with recurrent epididymitis?
}

\author{
Ching-Heng Yen, Chun-Te Lee, Chung-Jen Su and Hua-Cheng Lo*
}

\begin{abstract}
A 53-year-old Taiwanese male had several episodes of left epididymitis with hydrocele refractory to antibiotic treatment. Partial epididymectomy plus preventive vasectomy were planned, and, incidentally, an ill-defined nodule was found lying on the tunica vaginalis near the epididymal head. The pathological diagnosis was malignant mesothelioma of the tunica vaginalis testis. Radical orchiectomy with wide excision of the hemi-scrotal wall was performed. So far, there is no evidence of recurrence after more than 3 years of follow-up. Malignant tumor should be considered in the case of recurrent epididymitis refractory to empirically effective antibiotic treatment. Although the nature of this tumor is highly fatal, the malignancy can possibly be cured by early and aggressive surgical treatment.
\end{abstract}

Keyword: Malignant mesothelioma of the tunica vaginalis testis, Epididymitis, Hydrocele

\section{Background}

Malignant mesothelioma of the tunica vaginalis testis is a rare tumor. Since the first case report, fewer than 100 cases have been reported to date [1,2]. Most of these cases presented with nonspecific symptoms, such as a painless scrotal mass associated with hydrocele, even in the advanced stage. The pathogenesis of this malignant neoplasm is unclear and is mostly related to asbestos exposure [3], as well as a long-lasting hydrocele [4]. An early preoperative diagnosis is difficult to obtain, and a few cases have even been suspected to be epididymitis [5]. We hereby report a case of malignant mesothelioma of the tunica vaginalis testis that mimicked epididymitis with hydrocele.

\section{Case presentation}

About 3 years ago, a 53-year-old man was referred to our hospital with the chief complaint of a repetitive painful nodule over the left scrotum. He had visited a local medical clinic and had been treated with empirical antibiotics with the diagnosis of epididymitis. The patient was

\footnotetext{
* Correspondence: huachenglou@gmail.com

Division of Urological Surgery, Department of Surgery, Song-Shan Armed Forces General Hospital, No. 131, JianKang Rd., SongShan Dist., Taipei City 105, Taiwan
}

(c) 2012 Yen et al.; licensee BioMed Central Ltd. This is an Open Access article distributed under the terms of the Creative Commons Attribution License (http://creativecommons.org/licenses/by/2.0), which permits unrestricted use, distribution, and reproduction in any medium, provided the original work is properly cited. sexually active and reported no lower urinary tract symptoms. He denied any history of exposure to asbestos or scrotal trauma. First, scrotal ultrasonography was arranged to rule out an abscess. The ultrasonographic pictures (Figure 1A) showed a left scrotal mild hydrocele and an increased thickness of the scrotal wall as seen in epididymitis. Following modification of antibiotic treatment, the symptoms subsided for about one year.

One year later the patient returned with the problem of several episodes of scrotal pain and recurrent epididymitis. This time, antibiotic therapy had a limited therapeutic effect, and the inflammatory symptoms fluctuated, but never subsided. Thus, we decided to perform partial epididymectomy plus a preventive vasectomy. Prior to surgery, follow-up scrotal ultrasonography demonstrated a hypoechoic lesion of about $0.5 \mathrm{~cm}$ in size over the left epididymal head (Figure 1B), and inflammatory granuloma was suspected. During the operation, an ill-defined nodule (measuring $2 \times 1 \times 1 \mathrm{~cm}$ ) was found lying on the tunica vaginalis near the epididymal head. The nodule was excised from the tunica vaginalis and a partial epididymectomy plus a preventive vasectomy were performed.

The pathological report showed unusual neoplastic change of the tunica vaginalis. Under microscopic examination, the nodule showed a picture of malignant 


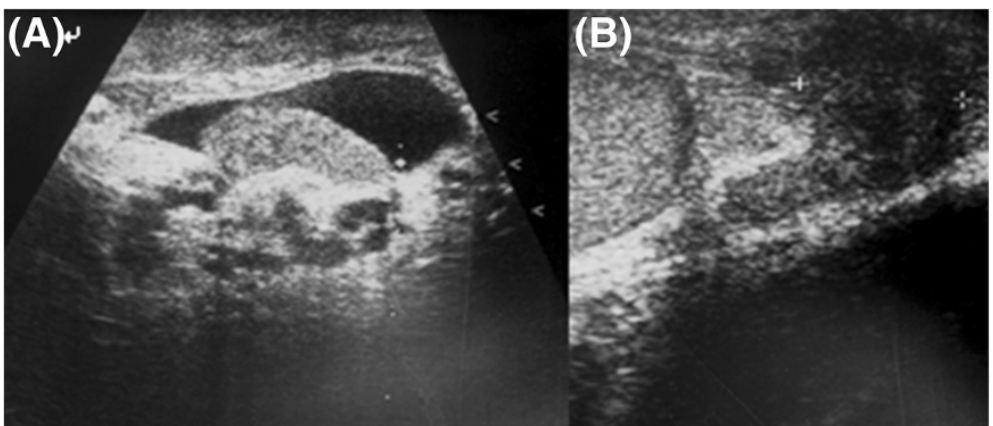

Figure 1 Scrotal ultrasound image from 1 year ago (A) and prior to surgery (B). (A) mild hydrocele and increased thickness of the left tunica vaginalis; (B) a hypoechoic lesion of approximately $0.5 \mathrm{~cm}$ in size over the left epididymal head.

mesothelioma, well-differentiated, accompanied by tubulopapillary morphological features. These tumor cells were rounded or a cuboidal pattern with nuclear atypia, prominent nucleoli and a diffuse infiltrating pattern (Figure 2A). By immunohistochemical staining, the cells were found to be consistently positive for cytokeratin stain and calretenin stain but negative for CEA stain (Figure 2B-D), and the diagnosis of malignant mesothelioma of the tunica vaginalis testis was confirmed.

Once the pathologic diagnosis was established, complete workup of the tumor staging was arranged. By computerized tomography, no evidence of local invasion or metastasis in the adjacent lymph nodes was demonstrated. Subsequently, radical orchiectomy with wide excision of the hemi-scrotal wall was performed. The patient was discharged and so far (after over 3 years of follow-up) there is no evidence of local or distant recurrence.

\section{Discussion}

Malignant mesothelioma of the tunica vaginalis testis is an uncommon disease and is usually described as originating from the pleura, pericardium, and peritoneum. Malignant mesothelioma of the tunica vaginalis testis is extremely rare. Since the first case was described in 1957 [6], about 100 cases have been reported to date. Although this tumor is most often seen in patients between the ages of 55 and 75 years, $10 \%$ of patients are younger than 25 years [5]. The pathogenesis of malignant mesothelioma has a strong relationship with occupational exposure to asbestos and long-lasting hydrocele. However, several cases including ours have been reported, in which there is no history of exposure to asbestos. In a review of non-asbestos-related malignant mesothelioma, Peterson and associates [7] found that chronic inflammatory processes have also been suggested to be possible causes of malignant mesothelioma.

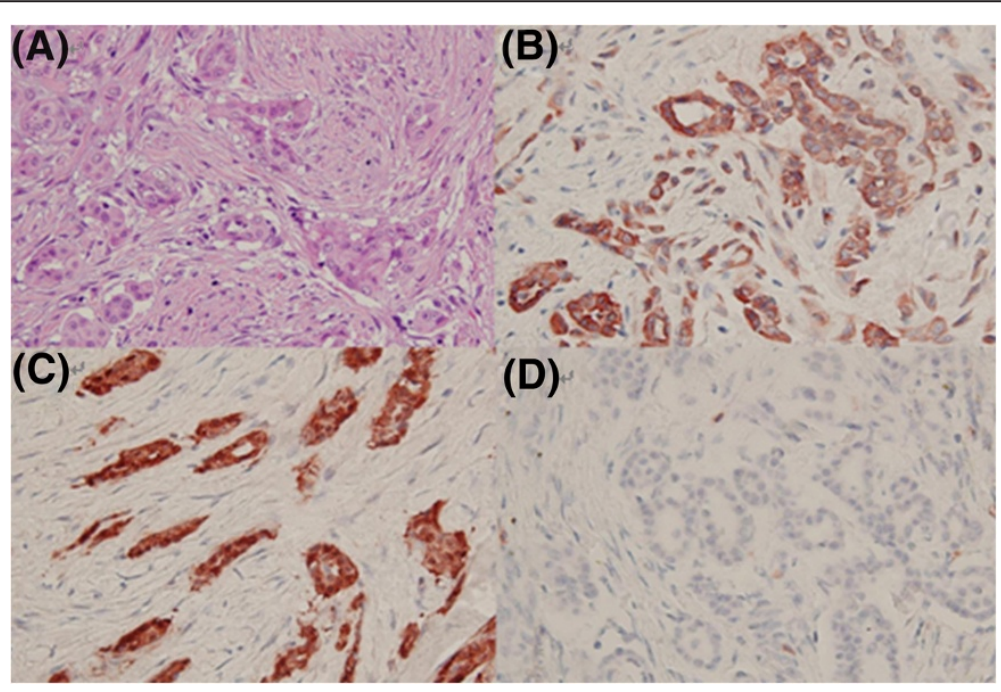

Figure 2 Histological and immunohistochemical features of malignant mesothelioma of the tunica vaginalis testis. (A) The tumor cells are rounded or cuboidal with nuclear atypia, prominent nucleoli and a diffuse infiltrating pattern (haematoxylin and eosin stain $\times 100)$; (B) positive for cytokeratin stain; (C) positive for calretenin stain; (D) negative for CEA stain. 
Previous histories of lung diseases, such as recurrent acute lung infections, active pulmonary tuberculosis, recurrent pleural effusion of unknown origin, and recurrent spontaneous pneumothorax, have been noted in patients who are victims of pleural malignant mesothelioma and have never been exposed to asbestos. In addition, in the peritoneum, malignant mesothelioma also occurs in patients with repeated pneumoperitoneum resulting from pulmonary tuberculosis, those with a long history of severe persistent and recurrent diverticulitis, and those with a long history of familial Mediterranean fever with recurrent peritonitis.

The main clinical symptom of these patients with malignant mesothelioma of the tunica vaginalis testis is a painless scrotal mass with hydrocele. Diagnosis is mostly made intraoperatively or postoperatively owing to the nonspecific symptoms and the absence of a tumor marker before surgery. By reviewing evidence obtained by searching PubMed for articles on malignant mesothelioma of the tunica vaginalis testis between 1998 and August 2012 [1-5,8-33], and including our case, we studied a total of 101 cases to analyze the possible clinical manifestations or preoperative diagnoses of this malignancy (Table 1). The common preoperative impressions or diagnoses were hydrocele (49.5\%), suspicious testicular tumor (36.6\%), inguinal hernia (5.9\%), epididymitis (3\%), spermatocele (2\%), testicular torsion (2\%), and posttraumatic testicular lesion (1\%). Epididymitis is rarely presented in malignant mesothelioma of the tunica vaginalis testis, and only three cases have been reported.

In general, there are several causes of epididymal inflammation: infection, trauma, autoimmune disease, vasculitis, and idiopathic. The pathophysiology of epididymitis remains unclear, although it is postulated to occur secondary to retrograde flow of infected urine into the ejaculatory duct. Epididymitis is characterized by inflammation of the epididymis presenting as pain and swelling, generally occurring on one side and developing over several days. Multiple objective findings of epididymitis have been identified

Table 1 Common preoperative diagnoses of mesothelioma of the tunica vaginalis testis

\begin{tabular}{llll}
\hline $\begin{array}{l}\text { Preoperative } \\
\text { diagnosis }\end{array}$ & $\begin{array}{l}\text { Case } \\
\text { number }\end{array}$ & $\begin{array}{l}\text { Percentage } \\
\mathbf{( \% )}\end{array}$ & Reference \\
\hline Hydrocele & 50 & 49.5 & {$[1-5,8,10,14-16,20,21,23,32,33]$} \\
\hline Testicular tumor & 37 & 36.6 & {$[3,5,9,13,17,18,21-26,28-31]$} \\
\hline Inguinal hernia & 6 & 5.9 & {$[5,11,23,27]$} \\
\hline Epididymitis & 3 & 3 & {$[5,12]$, and our study } \\
\hline Spermatocele & 2 & 2 & {$[5]$} \\
\hline Testicular torsion & 2 & 2 & {$[19,27]$} \\
\hline Post-traumatic & 1 & 1 & {$[5]$} \\
testicular lesion & & & \\
\hline Total number & 101 & 100 & \\
\hline
\end{tabular}

and, in variable degrees may include positive urine cultures, fever, erythema of the scrotal skin, leukocytosis, urethritis, hydrocele, and involvement of the adjacent testis [34]. The inflammation of the epididymis frequently involves the surrounding tunica vaginalis and induces reactive hydrocele and serosal injury. Persistent serosal injury, as in epididymitis, hydrocele, hematocele, and inguinal hernia sacs, may cause reactive hyperplasia of the mesothelial lining and submesothelial fibrosis. The combination of the two responses may easily result in histological characteristics mimicking malignant mesothelioma, papillae and small tubules, solid nests and cords extending into the underlying reactive connective tissue, simulating invasion [35]. Following long-term or repetitive inflammatory stimuli, the reactive mesothelial hyperplasia might possibly be further transformed into malignant mesothelioma. Therefore, like pleural and peritoneal malignant mesothelioma, chronic inflammation/infection might provide a hypothetical mechanism of tumorigenesis linking recurrent epididymitis with malignant mesothelioma of the tunica vaginalis testis.

Because there is no precise diagnostic modality available, several methods have been applied for early detection prior to surgery. The most popular diagnostic tool is scrotal ultrasound. A series of sonographic features in scrotal mesothelioma were reviewed for preoperative diagnosis. In addition to hydrocele being commonly presented, scrotal mesothelioma could be associated with an extratesticular mass with atypical sonographic features [36]. Color Doppler ultrasound might have the potential to be used to unveil the vascular characteristics of malignant mesothelioma [32,37]. However, either hypervascularity or hypovascularity in mass lesions has been described in articles, and thus color Doppler ultrasound could not be used as a definitive diagnostic tool. Preoperative diagnosis using aspiration cytology of the hydrocele fluid has been described in cases of rapidgrowing hydrocele in the elderly [38]. Considering the sensitivity of cytology and the potential risk of metastasis, the routine use of fine needle aspiration for preoperative diagnosis is still under debate. Therefore, there seems to be no definite diagnostic modality established prior to surgery, and so far definite diagnosis usually warrants surgical exploration as well as pathological examination with special immunohistochemical stains.

Treatment for malignant mesothelioma of the tunica vaginalis testis is still not established. Some authors have adopted the treatment of pleural mesothelioma [39] for patients with paratesticular malignant mesothelioma, but this is of limited therapeutic efficacy. Surgery should be the first-line therapy in cases of early disease. Radical inguinal orchidectomy appears to be the optimum treatment. Local resection of the hydrocele wall is associated with a local recurrence rate of $36 \%$, and hemiscrotectomy is often required for local control, 
whereas local recurrence after orchidectomy is reported in 10.5 to $11.5 \%$ of patients [5]. Adjuvant therapy with systemic chemotherapy and radiotherapy might provide a better overall survival rate in advanced disease [40], but this has not been fully assessed yet. Malignant mesothelioma of the tunica vaginalis testis is an aggressive tumor with high recurrence and mortality rates; about $52 \%$ of patients develop local recurrence or metastasis and $40 \%$ of patients die from their disease, with a median survival of 24 months [5,41]. Age (< 60 years) and organconfined disease at diagnosis are significant factors correlated with survival [5]. As our patient has remained well and free of recurrence or metastasis for more than 3 years, we believe that early aggressive surgical excision (radical orchiectomy with wide excision of the hemi-scrotum) is effective and necessary for successful treatment.

\section{Conclusion}

In this case report, we have demonstrated that malignant mesothelioma of the tunica vaginalis testis might mimic epididymitis. We also proposed a hypothetical correlation between epididymitis and paratesticular malignant mesothelioma. Malignancy should be considered in the differential diagnoses, especially in cases of recurrent epididymitis refractory to empirically effective antibiotic treatment. Definitive diagnosis warrants surgical exploration. Once a pathological diagnosis is confirmed, radical orchiectomy with hemiscrotectomy should be performed as soon as possible. Although the nature of this tumor is highly fatal, the malignant disease could be potentially cured by early and aggressive surgical treatment.

\section{Consent}

Written informed consent was obtained from the patient for publication of this case report and any accompanying images. A copy of the written consent is available for review by the Editor-in-Chief of this journal.

\section{Competing interests}

The authors declare that they have no competing interests.

\section{Authors' contributions}

$\mathrm{CHY}$ and $\mathrm{HCL}$ were responsible for delivering patient care. CTL and CJS provided opinions in diagnosis and treatment. $\mathrm{CHY}$ contributed towards to drafting the manuscript while HCL provided overall supervision and edited the final version of the manuscript. All authors read and approved the final manuscript.

\section{Authors' information}

Division of Urological Surgery, Department of Surgery, Song-Shan Armed Forces General Hospital, Taipei, Taiwan.

Received: 29 June 2012 Accepted: 26 October 2012

Published: 9 November 2012

\section{References}

1. Chen $J$, Hsu YH: Malignant mesothelioma of the tunica vaginalis testis: a case report and literature review. Kaohsiung J Med Sci 2009, 25:77-81.

2. Garcia de Jalon A, Gil P, Azua-Romeo J, Borque A, Sancho C, Rioja LA: Malignant mesothelioma of the tunica vaginalis. Report of a case without risk factors and review of the literature. Int Urol Nephrol 2003, 35:59-62.

3. Gupta NP, Agrawal AK, Sood S, Hemal AK, Nair M: Malignant mesothelioma of the tunica vaginalis testis: a report of two cases and review of literature. J Surg Oncol 1999, 70:251-254.

4. Gurdal M, Erol A: Malignant mesothelioma of tunica vaginalis testis associated with long-lasting hydrocele: could hydrocele be an etiological factor? Int Urol Nephrol 2001, 32:687-689.

5. Plas E, Riedl CR, Pfluger H: Malignant mesothelioma of the tunica vaginalis testis: review of the literature and assessment of prognostic parameters. Cancer 1998, 83:2437-2446.

6. Barbera V, Rubino M: Papillary mesothelioma of the tunica vaginalis. Cancer 1957, 10:183-189.

7. Peterson JT Jr, Greenberg SD, Buffler PA: Non-asbestos-related malignant mesothelioma. a review. Cancer 1984, 54:951-960.

8. Hamm M, Rupp C, Rottger P, Rathert P: Malignant mesothelioma of the tunica vaginalis testis. Chirurg 1999, 70:302-305.

9. Harmse JL, Evans AT, Windsor PM: Malignant mesothelioma of the tunica vaginalis: a case with an unusually indolent course following radical orchidectomy and radiotherapy. Br J Radiol 1999, 72:502-504.

10. Haga K, Shinohara N, Harabayashi T, Demura T, Koyanagi T: Is serum hyaluronic acid level useful for evaluating the clinical course of malignant mesothelioma of the tunica vaginalis? BJU Int 1999, 84:729-730.

11. Kanazawa S, Nagae T, Fujiwara T, Fujiki R, Mukai N, Sugihara Y, Yamaguchi N, Ohtani H, Higami Y, Ikeda T, Tsunoda T: Malignant mesothelioma of the tunica vaginalis testis: report of a case. Surg Today 1999, 29:1106-1110.

12. Uria Gonzalez-Tova J, Escalera Almendros C, Sanchez Macias J, Areal Calama J, Sanfeliu Cortes F, Ibarz Servio L, Saladie Roig JM: Malignant mesothelioma of the tunica vaginalis. Actas Urol Esp 2000, 24:757-760. Article in Spanish.

13. Ferri E, Azzolini N, Sebastio N, Salsi P, Meli S, Cortellini P: Unusual case of mesothelioma of the tunica vaginalis associated with prostatic adenocarcinoma]. Minerva Urol Nefrol 2000, 52:33-35. Article in Italian.

14. Iczkowski KA, Katz G, Zander DS, Clapp WL: Malignant mesothelioma of tunica vaginalis testis: a fatal case with liver metastasis. J Urol 2002, 167:645-646.

15. Bruno C, Minniti S, Procacci C: Diagnosis of malignant mesothelioma of the tunica vaginalis testis by ultrasound-guided fine-needle aspiration. J Clin Ultrasound 2002, 30:181-183.

16. Abe K, Kato N, Miki K, Nimura S, Suzuki M, Kiyota H, Onodera S, Oishi Y: Malignant mesothelioma of testicular tunica vaginalis. Int J Urol 2002, 9:602-603.

17. Sawada K, Inoue K, Ishihara T, Kurabayashi A, Moriki T, Shuin T: Multicystic malignant mesothelioma of the tunica vaginalis with an unusually indolent clinical course. Hinyokika Kiyo 2004, 50:511-513.

18. Mak CW, Cheng TC, Chuang SS, Wu RH, Chou CK, Chang JM: Malignant mesothelioma of the tunica vaginalis testis. Br J Radiol 2004, 77:780-781.

19. Pelzer A, Akkad T, Herwig R, Rogatsch H, Pinggera GM, Bartsch G, Rehder P: Synchronous bilateral malignant mesothelioma of tunica vaginalis testis: early diagnosis. Urology 2004, 64:1031.

20. Shimada S, Ono K, Suzuki Y, Mori N: Malignant mesothelioma of the tunica vaginalis testis: a case with a predominant sarcomatous component. Pathol Int 2004, 54:930-934.

21. Gorini G, Pinelli M, Sforza V, Simi U, Rinnovati A, Zocchi G: Mesothelioma of the tunica vaginalis testis: report of 2 cases with asbestos occupational exposure. Int J Surg Pathol 2005, 13:211-214.

22. Wang MT, Mak CW, Tzeng WS, Chen JC, Chang JM, Lin CN: Malignant mesothelioma of the tunica vaginalis testis: unusual sonographic appearance. J Clin Ultrasound 2005, 33:418-420.

23. Schure PJ, van Dalen KC, Ruitenberg HM, van Dalen T: Mesothelioma of the tunica vaginalis testis: a rare malignancy mimicking more common inguino-scrotal masses. J Surg Oncol 2006, 94:162-164. discussion 161.

24. Hatzinger M, Hacker A, Langbein S, Grobholz R, Alken P: Malignant mesothelioma of the testes. Aktuelle Urol 2006, 37:281-283. Article in German. 
25. Thomas C, Hansen T, Thuroff JW: Malignant mesothelioma of the tunica vaginalis testis. Urologe A 2007, 46:538-540. Article in German.

26. Al-Qahtani M, Morris B, Dawood S, Onerheim R: Malignant mesothelioma of the tunica vaginalis. Can J Urol 2007, 14:3514-3517.

27. Candura SM, Canto A, Amatu A, Gerardini M, Stella G, Mensi M, Poggi G: Malignant mesothelioma of the tunica vaginalis testis in a petrochemical worker exposed to asbestos. Anticancer Res 2008, 28:1365-1368.

28. Ikegami Y, Kawai N, Tozawa K, Hayashi Y, Kohri K: Malignant mesothelioma of the tunica vaginalis testis related to recent asbestos. Int J Urol 2008, 15:560-561.

29. Matsuzaki K, Nakajima T, Katoh T, Kitoh H, Mizoguchi K, Akakura K, Inoue T: Malignant mesothelioma of the tunica vaginalis: a case report. Hinyokika Kiyo 2008, 54:629-631. Article in Japanese.

30. Goel A, Agrawal A, Gupta R, Hari S, Dey AB: Malignant mesothelioma of the tunica vaginalis of the testis without exposure to asbestos. Cases J 2008, 1:310.

31. Al-Salam S, Hammad FT, Salman MA, AlAshari M: Expression of Wilms tumor-1 protein and CD 138 in malignant mesothelioma of the tunica vaginalis. Pathol Res Pract 2009, 205:797-800.

32. Aggarwal P, Sidana A, Mustafa S, Rodriguez R: Preoperative diagnosis of malignant mesothelioma of the tunica vaginalis using Doppler ultrasound. Urology 2010, 75:251-252.

33. Kato R, Matsuda Y, Maehana T, Miyao N, Konishi Y, Kon S: Intrascrotal malignant mesothelioma diagnosed after surgery for hydrocele testis: a case report. Hinyokika Kiyo 2012, 58:45-48. Article in Japanese.

34. Tracy CR, Steers WD, Costabile R: Diagnosis and management of epididymitis. Urol Clin North Am 2008, 35:101-108.

35. Amin MB: Selected other problematic testicular and paratesticular lesions: rete testis neoplasms and pseudotumors, mesothelial lesions and secondary tumors. Mod Pathol 2005, 18(Suppl 2):S131-S145.

36. Wolanske K, Nino-Murcia M: Malignant mesothelioma of the tunica vaginalis testis: atypical sonographic appearance. J Ultrasound Med 2001, 20:69-72.

37. Boyum J, Wasserman NF: Malignant mesothelioma of the tunica vaginalis testis: a case illustrating Doppler color flow imaging and its potential for preoperative diagnosis. J Ultrasound Med 2008, 27:1249-1255.

38. Gupta R, Dey P, Vasishtha RK: Fine needle aspiration cytology in malignant mesothelioma of the tunica vaginalis testis. Cytopathology 2011, 22:66-68.

39. Stahel RA, Weder W, Felip E, Group EGW: Malignant pleural mesothelioma: ESMO clinical recommendations for diagnosis, treatment and follow-up. Ann Oncol 2009, 20(Suppl 4):73-75.

40. Lopez JI, Angulo JC, Ibanez T: Combined therapy in a case of malignant mesothelioma of the tunica vaginalis testis. Scand J Urol Nephrol 1995, 29:361-364

41. Jones MA, Young RH, Scully RE: Malignant mesothelioma of the tunica vaginalis. A clinicopathologic analysis of 11 cases with review of the literature. Am J Surg Pathol 1995, 19:815-825.

doi:10.1186/1477-7819-10-238

Cite this article as: Yen et al:: Malignant mesothelioma of the tunica vaginalis testis: a malignancy associated with recurrent epididymitis? World Journal of Surgical Oncology 2012 10:238.

\section{Submit your next manuscript to BioMed Central and take full advantage of:}

- Convenient online submission

- Thorough peer review

- No space constraints or color figure charges

- Immediate publication on acceptance

- Inclusion in PubMed, CAS, Scopus and Google Scholar

- Research which is freely available for redistribution

Submit your manuscript at www.biomedcentral.com/submit
C Biomed Central 